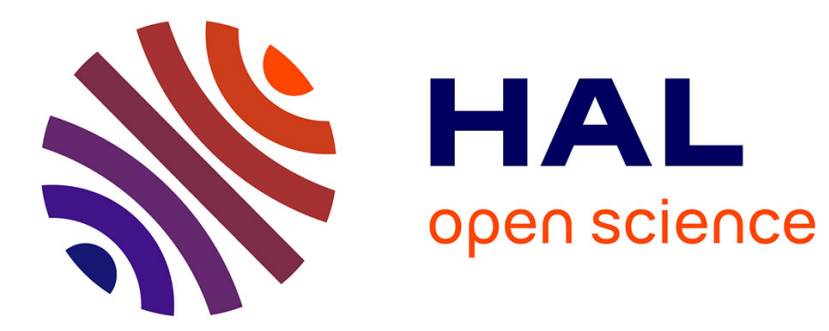

\title{
Planning process for pooling integration in city logistics
}

\author{
Parisa Dolati Neghabadi, Marie-Laure Espinouse, Karine Evrard Samuel
}

\section{To cite this version:}

Parisa Dolati Neghabadi, Marie-Laure Espinouse, Karine Evrard Samuel. Planning process for pooling integration in city logistics. 4th International Conference on Logistics Operations Management (GOL 2018), Apr 2018, Le Havre, France. pp.10 Pages, 10.1109/GOL.2018.8378097 hal-01876001

\section{HAL Id: hal-01876001 \\ https://hal.science/hal-01876001}

Submitted on 18 Sep 2018

HAL is a multi-disciplinary open access archive for the deposit and dissemination of scientific research documents, whether they are published or not. The documents may come from teaching and research institutions in France or abroad, or from public or private research centers.
L'archive ouverte pluridisciplinaire HAL, est destinée au dépôt et à la diffusion de documents scientifiques de niveau recherche, publiés ou non, émanant des établissements d'enseignement et de recherche français ou étrangers, des laboratoires publics ou privés. 


\section{Planning Process for Pooling Integration in City Logistics}

\author{
Parisa DOLATI NEGHABADI \\ Univ. Grenoble Alpes, CNRS \\ Grenoble INP, G-SCOP \\ Grenoble, France \\ Parisa.Dolatineghabadi@grenoble- \\ inp.fr
}

\author{
Marie-Laure ESPINOUSE \\ Univ. Grenoble Alpes, CNRS \\ Grenoble INP, G-SCOP \\ Grenoble, France \\ Marie-Laure.Espinouse@g- \\ scop.grenoble-inp.fr
}

\author{
Karine EVRARD SAMUEL \\ Univ. Grenoble Alpes, CNRS \\ Grenoble INP, CERAG \\ Grenoble, France \\ Karine.Samuel@grenoble-inp.fr
}

\begin{abstract}
City logistics comprises all freight transportation and distribution activities in urban areas and aims to raise the prosperity of a city while mitigating the negative externalities. Hence, resources scarcity and the need for large investments on initiatives implementation have driven researchers toward collaboration as a promising solution. In conjunction with this, pooling has been emerged as a systematic collaborative solution which is defined as the mutual and contemporary use of resources while all involved stakeholders have direct influence on decision making during the whole process. To this end, a comprehensive approach is required to explain how pooling is achievable in urban area. For this reason, this article focuses on the development of a general framework to discuss required steps to integrate pooling into the city logistics system. This framework includes two main parts: the first part contributes to diagnose the current status of the system while the second part discusses organizational planning steps for the three strategic, tactical and operational level. Furthermore, in the first part of the framework we propose a new concept, Typology of Flow (ToF), which is presented to study the main elements of the city logistics system and consequently, the urban flows with more attention into details. The information provided by this concept will help to choose the most compatible solutions for pooling integration in city logistics.
\end{abstract}

Keywords - City Logistics, Pooling, Planning Framework, Typology of Flow.

\section{INTRODUCTION}

Around $70 \%$ of the world's population will live in cities until 2050 [1]. This urbanization is ramping up more in European Union as it is estimated that the population live in cities will reach $80 \%$ by 2020 [2]. Consequently, economic growth, improving urbanization, environmental effects, urban unemployment, urban freight transport efficiency and cities' development will be affected by logistics activities in urban area. City logistics, considered as the last stage of supply chain management, comprises all transportation and distribution activities in urban areas [3]. Appropriate and efficient city logistics design and planning will have a great impact on social welfare $[4,5]$. The main objective of city logistics efforts is to elevate a city's prosperity while alleviating its emerging negative consequences such as pollution, traffic, fatality risk and destructive environmental effects. The most challenging difficulties in city logistics are high number of involved stakeholders and their contradictory objectives, diversity of flows, the dynamics of the system, negative environmental impacts, tasks dependency, demands increase regarding ecommerce growth, competition leading toward zero delay, regulation leading up to access restriction, concerns to avoid fatality caused by distribution in the cities, different urban geography and complicated relation between all actors and actions.

To cope with these issues, different city logistics' initiatives and measures have been emerged. Generally, their objective is to ensure efficient freight movements in urban area whilst satisfying consumer and business demand and minimizing the externalities [6]. Additionally, with regard to the importance of freight transportation in cities in order to reach economic development, involved stakeholders have started to contribute to an efficient urban distribution system by providing new services [7, 8]. Nevertheless, as the required resources (such as land, vehicles and personnel) are either scarce or expensive in urban area and the implementation of the proposed initiatives needs large investments, collaboration has been introduced as a promising solution [9]. Thereby, collaboration has been grouped to three different stages: transactional collaboration, information collaboration and decisional collaboration [10]. Collaboration could lead stakeholders towards resource sharing; here, sharing means the joint or alternate use of resources. In city logistics, resource sharing is divided into three groups: vehicle sharing, infrastructure sharing and route sharing [11]. Although collaboration is an interesting initiative to be applied, but it still demands to be more developed through decision support systems with respect to the public and private stakeholders. Data sharing is also a key issue these days, which needs more investigation and supports [12]. In recent years, pooling has been emerged as a systematic collaborative solution which is defined as the mutual and contemporary use of resources while all stakeholders have direct influence on decisions making and are well-informed about all processes [9]. 
However, pooling concept has been conceptually discussed during years, but it still lacks a step-by-step process to explain how it could be integrated into the city logistics system. Hence, the objective of this article is to focus on the development of a process to integrate pooling in city logistics as a systematic collaboration. Along with this, a general framework is presented in which requirements to construct a pooled system are described. This framework includes two different parts: the first part discusses the required information, to better plan an effective pooled system; the second part proposes an innovative approach in order to describe decisions-making hierarchy to integrate pooling in the complicated city logistics system with regard to the decisional collaboration.

The first part concentrates on the city logistics system identification which would result in urban flows recognition. In fact, the objective of this analysis is not only to elaborately discuss and quantify urban flows but also to provide a detailed study about flows to identify whether a flow is poolable or not and then if it is, with which other flows. This information would lead up to diagnose the actual system. For this purpose, the concept "Typology of Flow" (ToF) is proposed which its contribution is to identify main elements of the city logistics system. These elements are expressed as fundamental components and supportive components. Fundamental components construct the main skeleton of the system and they are out of stakeholders' influence. In contrast, supportive components are the available solutions of storage and means of transport which have been already proposed and can be chosen regarding stakeholders' need and objectives. The aim of proposing this ToF is to classify the different types of flows that pass through urban areas by identifying their features in order to facilitate the organization of last mile delivery and distribution [20, 27, and 29]. To the best of our knowledge, this study is the first effort that introduces the concept of "ToF". More details are provided in the section IV.

Since integrating pooling in an existing system in which each member has its own process is not achievable without an organizational planning procedure, the main objective of the second part is to analyze the impacts of decisions taken in each level of decision making and also to identify feedbacks sequence in the whole procedure of pooling. The rest of this article is organized as follows: section II provides a review on pooling and its applications. Section III describes the proposed framework. Section IV introduces Typology of Flow and its main elements; consequently, Section V concludes the discussed approach and presents future research directions.

The rest of this article is organized as follows: section II provides a review on pooling and its applications. Section III describes the proposed framework. Section IV introduces Typology of Flow and its main elements; consequently, Section $\mathrm{V}$ concludes the discussed approach and presents future research directions.

\section{POOLING CONCEPT}

Since 2000, logistics pooling has been emerged in supply chain management [13]. Pooling is defined as sharing and mutual use (either contemporary or permanent) of resources (such as vehicles, warehouse, platform and land use, etc.) to achieve the personal objectives such as reducing logistics cost and the environmental impacts and increasing efficiency. Several key factors are needed to implement an efficient pooled system; generally, these factors are linked to the presence of resources, motivation and specific capabilities [14]. A high collaboration among stakeholders is compulsory to manage and move forward pooling; in other words, agreement and commitment of all involved stakeholders are essential to achieve a successful pooled system [10]. In the literature, logistics pooling is referred to warehouse pooling and transport pooling. As the application of pooling, carpooling is one of its well-known usages; recently, GoodsPooling, equivalent to carpooling concept is emerged in order to integrate daily home/work trips to handle pickup and delivery activities in urban goods movement [15]. Warehouse pooling has been also discussed to show how the implementation of pooling concept in warehousing improves performance and enhances the ecoefficiency of logistics systems [16].

Pooling in city logistics is defined as mutualizing required resources to perform last mile delivery and distribution activities in urban areas. However, pooling concept in the city logistics domain is relatively new, but it has been studied under different definitions and forms [9]: Information pooling concentrating on e-commerce and home delivery [17], delivery system pooling focusing on Urban Distribution Centre [18], and resource pooling between logistics service provider in urban area [9]. In spite of these studies, precise understanding and analysis are still requested to drive toward an efficient pooled system in city logistics.

Pooling integration not only has the same difficulties as the city logistics initiatives' implementation but also requires more organizational planning and consideration. In the literature, authors have focused on overall problematical aspects $[10,14$, 19], nevertheless to integrate pooling in the city logistics system with regard to the system complexity and the inevitable interconnectivity of actions, more information and knowledge about the logistics and transportation system are requested; therefore, the objective of this study is to bridge this gap by providing profound analysis of the city logistics system and its processes. The first step is to identify and analyse the current status, to gather needed information in order to diagnose actual system. To do so, some questions are asked: What is the main objective of pooling? Which information is required to analyse pooling possibilities in a system? Which decisions should be made to reach this goal? Who is responsible for each task? And when is the best time to take a reasonable action. To answer these questions comprehensively, a general framework is proposed under definition of decisional collaboration which concerns different planning and management decisions including strategic, tactical and operational planning [20]. This framework is a guidance to help to plan, organize, assess and implement pooling in city logistics [21]. This framework is discussed in the next section.

\section{PROPOSED FRAMEWORK}

However, there are relatively adequate discussion and high awareness about possible initiatives and innovative solutions in city logistics, but a systematic plan is still requested to discuss 


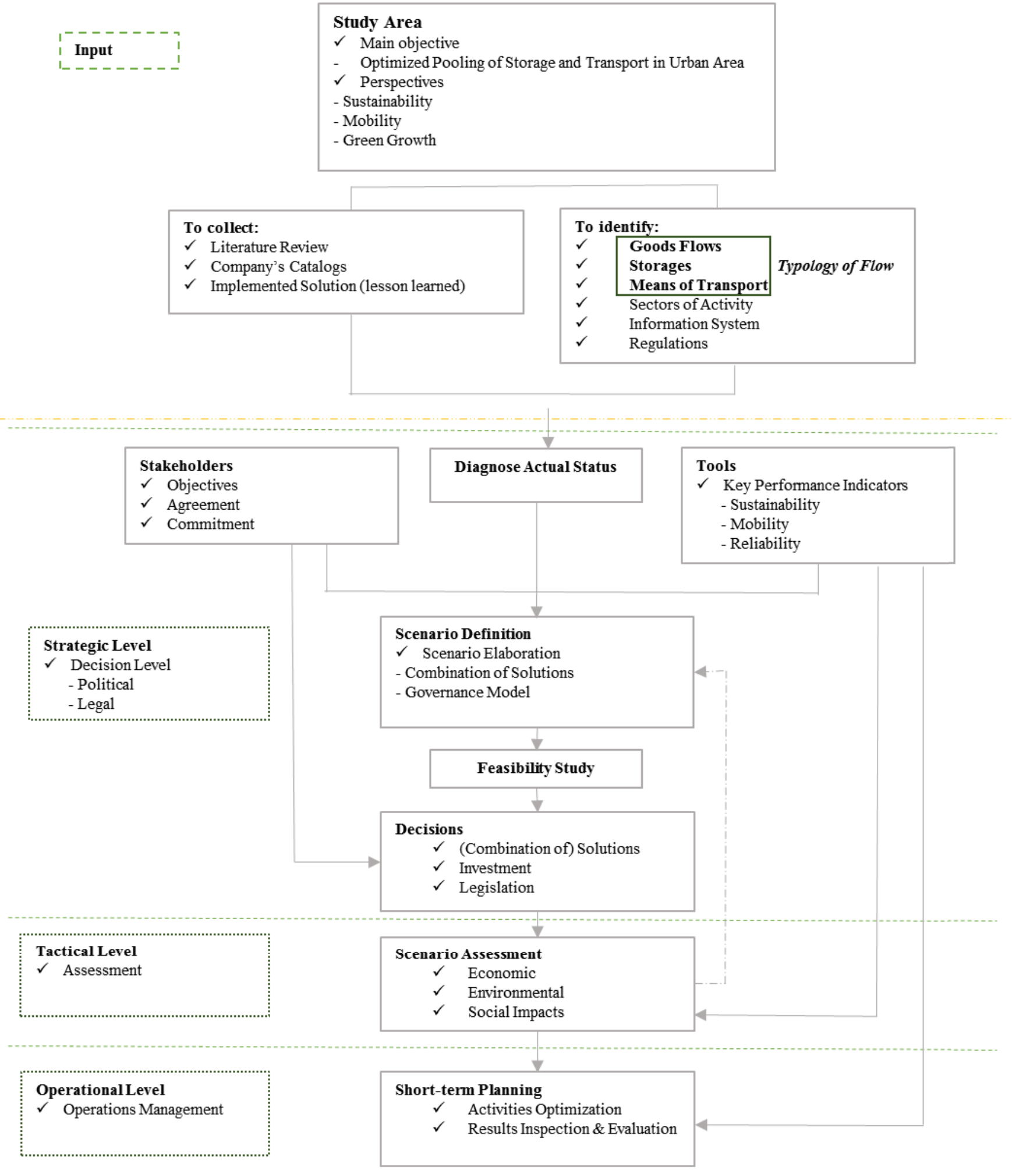

Figure 1. General framework explaining Pooling Integration in City Logistics 
decision making procedure and required steps to implement them efficiently. This lack of knowledge is encountered more when the ultimate objective is to redesign a complicated system [22]. Pooling demands evidently several changes in the actual system. Hence, its integration in city logistics, where functionality of the system is influenced by the decisions of multiple stakeholders, needs to be discussed and evaluated scrupulously [36]. Participatory planning processes are claimed as a valid opportunity for initiatives implementation in city logistics [23]. In this study, we propose a general framework (figure 1) whose objective is at first to identify the current status of the system and in the second step to explain the whole urban freight transportation decision making process with taking into account all stakeholders influence on decision making.

This framework includes two parts which are complementary and should be followed respectively. The first part is devoted to determine information needed as input to begin studying pooling integration in city logistics. Once required information is identified and the current status of system is diagnosed, the second part describes gradually how to achieve a pooled system through taking into account necessary considerations such as stakeholders' involvement in different steps, hierarchy of decisions and the importance of feedbacks during the procedure. To accomplish this part, the decisional collaboration stages containing strategic, tactical and operational planning are pursued to plan and manage decision making. Furthermore, this framework shows the dynamics of city logistics and its demand to maintain communication and exchange during collaboration [24].

To follow this framework, these questions must be primarily answered: what is the main objective of pooling in city logistics? Which perspectives are assumed to be reached through this planning? And what are their consequences in terms of decision making? Once the main objective is determined, two main groups of knowledge and information should be provided. First group is to collect already proposed ideas, implemented initiatives and lessons learned through literature review, companies' catalogue and implemented solutions' report. This database helps to know about the different aspects of the issue, to identify the difficulties which may be encountered and to also obtain a global vision about the whole process. In parallel with collection phase, the second group asks to identify the current system and available infrastructures and resources in urban area. The first part of the framework (data preparation part) provides the requisite input which would lead to diagnose the actual system.

At the second part, there are three phases, the first phase (strategic level) concerns long-term decisions planning and strategies. Referring to the pooling definition, recognizing involved stakeholders and their own objectives (which are almost contradictory) are required as a primary step in this phase. At the same time, identifying key performance indicators are required as important evaluation tools [25]. Obtained information about already implemented solutions, new ideas and system's requirements, make it possible to define scenarios in order to satisfy stakeholders' objectives and to drive towards defined perspectives. Scenarios could be the benchmarking of an existing solution, a new innovative solution or a combination of solutions. Furthermore, scenarios must be adequately elaborated by taking into account political and legal considerations, experts' opinions and geographical characteristics of the city. Then, the next step is to conduct a feasibility study to assess the practicality of the scenarios. The result of this study admits to make more effective decisions.

Tactical level is in charge of assessment phase. Scenarios in the last phase are assessed and evaluated regarding economic and environmental considerations through suitable key performance indicators in the scenario assessment step. This step comprises more detailed analysis and interpretations over the scenarios to provide a reliable passage towards operational phase. Here, a connecting point is appreciated between scenario assessment and scenario definition, it means scenarios could be adjusted in this level by returning to strategic level; in fact, a control loop is needed between these two steps as it is probable to neglect some impacting factors in scenario definition step, which could become clear during the implementation phase.

The last phase, operational level, includes the operations management of all related activities. In fact, not only optimizing daily activities is performed in this level, but also inspecting and evaluating results are spotted to qualify tasks efficiency and applicability. Since environmental concerns are a topical issue [26], regulation modification is predictable in the recent future, so revisions in operational level seem imperative to adjust the operations, if needed.

Since our objective is to study the possibility of urban flows pooling through available storages and means of transport alternatives in urban area, a comprehensive understanding about the city logistics system functionality is mandatory. With regard to the first part of the proposed framework and based on the knowledge acquired in the collection phase, we recognize six groups of information which might help to discover the city logistics system: goods flow, storages and means of transport alternatives, sector of activity, information system and regulations [11]. To characterize urban flows in order to study pooling possibility, we propose the term "Typology of Flow" which includes goods flow and storage and means of transport alternatives. As goods flows are the basic skeleton of city logistics, we call them fundamental elements and storage and means of transport are labelled supportive ones. The more detail on this concept is provided in the next section.

\section{TYPOLOGY OF FLOW}

City logistic involves numerous stakeholders each with its objectives and constraints. The city logistics system is often a conglomerate of sub systems, which are more or less interconnected, with rather independent functioning. In addition, the strong competition makes pooling a difficult task. Hence, an overall understanding of the system with regard to the functionality of each subsystem is crucial. This complexity of the system has motivated researchers to study this system deeply. In this context, Logistics Profile has been suggested to classify homogenous groups of urban zone according to three main attribute: agents' needs, city area features and product characteristics. The objective of this classification is to provide 
the possibility of best practices' transferability in city logistics [27]. A quantitative approach has been used as well in order to apply Logistics Profile concept and to analyse its applicability [1]. Another research has been conducted to present a typology based on an international overview of the geography of urban freight to classify global cities regarding their logistics systems and their city logistics initiatives [7]. In addition, another classification based on goods movement is proposed to identify urban flows. Three main flows have been identified as: interestablishment movements, end-consumer movements and urban management movements [28]. To the best of our knowledge, there is no research to discuss underlying layer of logistics and transportation system in urban area to recognize operational detail of these activities. Here, we discuss more deeply about the city logistics system to describe its main elements by introducing the concept "Typology of Flow". Three main elements are introduced by typology of flow: goods flows as fundamental elements since they construct the skeleton of the system; storage and means of transport alternatives as supportive elements which realize goods flows.

Regarding goods flows, a flow is created when a physical movement occurs between two points (origin and destination) according to a demand [30]. Therefore, a flow has three main components: origin/destination, demand of (final) customer and physical movement of goods, Figure 2. Physical movement corresponds to goods transfer; path is defined as a travel from an origin toward a destination according to a demand.
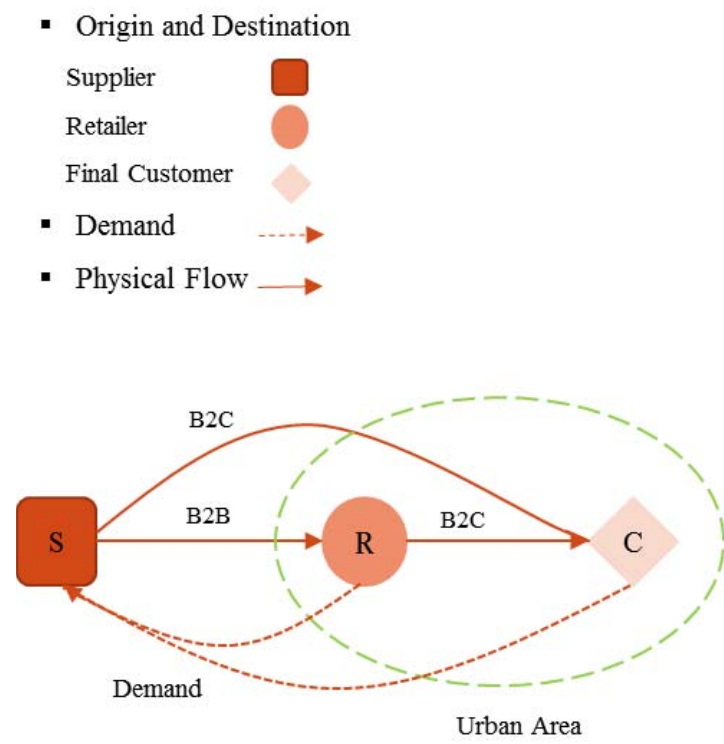

Figure 3. Flow components in the city logistics context.

Along with this definition, origin is considered as a departure point which could be a supplier, a storage or a warehouse located in the outskirts of the city or even a retailer in urban area. Destination is considered as a receiving point which could be either an intermediate storage or a final customer (retailer (B2B) or a home delivery (B2C) etc.) placed in urban area. It is supposed that origin is known and destination is then being known as soon as a demand arrives. Demand includes all requested information to enable dispatching a physical movement (orders quantity, exact destination, desired delivery time etc.). Goods can be any type of products demanded by clients. Goods, demand and path are fundamental component as they are the elementary bricks of the flow. Means of transport and storage alternatives are supportive components as they support logistics activities according to variable situations, Figure 3.

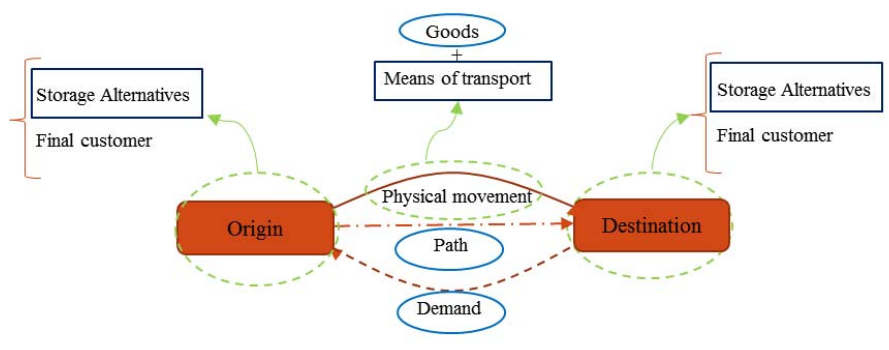

Figure 3. Typology of Flow.

To study each of these elements in detail and to identify their various types, let us ask several questions in order to drive towards features and role of each element. Results of this identification will be applied to recognize different types of flow. Questions are:

- Where are the origin and destination? What are their features and access condition?

- What is the component of a physical movement? What characteristics do they have?

- Which data can be achieved through a demand?

We return to goods characteristics, demand, and path to answer generally the above-mentioned questions. Goods characteristics include all physical features of a good and its handling conditions. Demand provides a detailed list of information about an order. Path focuses merely on transportation aspect in which the main required information about origin and destination points and their accessibility is listed. These three elements make it possible to distinguish different flows and to describe characteristics of a flow. More detailed description is provided in the following sections. This information leads to set up a template according to which we will be able to quantify urban flows and choose compatible and more suitable storage and means of transport solution in the aim of reaching a successful pooling.

\section{A. Goods characteristics}

Goods could be generally classified according to different criteria, domain and point of view. For instance, in the contract of sale, goods are classed into three groups: existing goods (goods which physically exist at the time of sale), future goods (goods to be acquired by seller) and contingent goods (good depends upon a contingency). In marketing, two general 
groups of goods have been identified: consumer goods and industrial goods. Consumer goods comprise conveniences goods (widely distributed and relatively inexpensive goods), shopping goods (a premium product occasionally bought by consumers), specialty goods (good that is extraordinary or unique) and unsought goods (goods that the consumer does not know about or does not normally think of buying). Industrial goods include raw materials, fabricating parts and materials [31]. Despite these classifications, in ToF, physical and intrinsic characteristics of goods are taken into consideration. Good's dimension, weight, packaging and transport unit are physical characteristics; some other features are related to intrinsic characteristics of goods such as being dangerous, precious, fragile and delicate or requiring special condition for handling. The features of this element are fixed as they do not change during the movement. Explanation for these features and proposed classification are described in appendix, table 1.

\section{B. Demand}

In ToF, demand is a general word which defines as a list of information achieved based an order. Demand for a good can change during different time horizon regarding changes in the orders (e.g. quantities, frequency and delivery lead time), or time windows. In addition, demand can change by external factors, for instance: demand pattern change, market change, seasonal demand pattern, etc. This is why the features of this element are considered variable. The more details about this classification and these features are provided in the appendix, table 2 .

\section{Path}

Path is considered as a route from an origin to a destination. Origin is supposed to be either in outskirts of the city or in the city center in the case where origin in an intermediate storage. Destination is located almost within the cities: an intermediate storage or final customers (retailer (B2B) or a home delivery (B2C) etc.). To explain our proposed classification for the path, we point out that any destination is located in a district within the city. Hereafter, we focus on districts instead of destinations to be able to consider supplementary factors that play important roles in classifying features of a path. These characteristics are classed as: districts characteristics which contain districts features such as its traffic statement, access condition, geographical condition and risk assessment; Reception point that is considered as the exact location of destination and its accessibility is identified as one of the important points in the path features. In the end, delivery area is spotted as the area in where the shipment would be unloaded. The availability of this area is one of the important factors to efficiently manage last mile delivery. The more details about these features are described in the appendix, table 3 .

\section{Storage Alternatives}

Storages and warehouses are considered as origin and destination points in the city logistics system. In this section we present their different types describing their features and functionalities. Two major types of storage are identified in the context of city logistics, table 4 . This classification is on the basis of their placement, either in the skirt of a city or in the urban area. Urban Distribution Centre (or Urban Consolidation Centre) is a rather large warehouse located at the edge of city centres, in close proximity to major access roads [16]. The second group comprises the innovative storages located in the centre of the city. Their goal is to streamline last mile delivery for both B2B and B2C sector. Proximity Logistics Spaces, Goods Reception Points, Urban Logistics Boxes and Mobile Depot are the most known solutions in this class. Each of these solutions is briefly descripted in the following parts.

Table 4. Storage solutions found in the literature

\begin{tabular}{|l|}
\hline Located in Suburban \\
\hline Urban Distribution Center (UDC) \\
Urban Consolidation Center (UCC) \\
\hline Located in City Center \\
\hline Proximity Logistics Spaces (PLS) \\
Goods Reception Points (GRP) \\
Urban Logistics Boxes (ULB) \\
Mobile Depot (MD) \\
\hline
\end{tabular}

Urban Distribution Center (UDC). The objective of UDC is to pool goods flow toward final customers into a city as far as possible and thereby decrease the movement of large vehicles in the city centre and/or dense areas. Cargos entered to this site have to be unloaded and then be loaded again (either after a wait or immediately) and be dispatched [32].

Proximity Logistics Spaces (PLS). PLS acts as micro-logistics platforms whose objective is to be an intermediate store where goods flows are broken in order to deliver the most possible number of customers which are in the same neighbourhoods (mostly when they are in dense area) at the same time. A garage, a parking space or a part/ whole of private commercial warehouses can be used as a PLS [32].

Goods Reception Points (GRP). GRP is assumed to be pick-up points which is coordinated by different actors in city centre (repair shop, appliances store etc.) in where goods are kept until final customers pick them up [32].

Urban Logistics Boxes (ULB). ULBs are small, mobile or fixed structures that act as temporary storage to keep goods until being picked up. They are now automatic and they provide easy access (run 24/24 hours) [32].

Mobile Depot $(M D)$. As its name signifies, it is a mobile warehouse which has a loading dock that allows to load the goods on light vehicles to manage last mile delivery in the challenging urban working conditions: narrow streets, mixed traffic, traffic congestion, congestion [33].

\section{E. Means of transport alternatives}

Nowadays, challenges in city logistics, especially in last mile delivery, have resulted in the development of various means of transport all around the world. Each means of 
transport can be used for several types of goods regarding goods characteristics and its required handling condition. These factors must be considered while vehicle selection and vehicle assignment as well where one has several options. The list of topical means of transport are as follow [14, 32, 34, and 35]:

- Tramways are proposed as a solution to combine passenger transport and freight transport in urban area by the goal of mobility optimization.

- Waterways are proposed as fluvial solutions for the cities in where there is a possibility to implement barges or express boats.

- Electrical vehicles are one of the most discussed solutions in city logistics these days, however, despite their advantage for being no emission, the need for a high investment in one hand and the technological constraints of batteries and limited capacity comparing traditional vehicles in the other hand cause complexity in their application for urban freight transportation.

- Cycles, bicycles, tricycles, cargo cycle, innovative cycle for heavy goods are initiatives which have been implemented to avoid city logistics externalities.

- Trolley has been introduced as well to be used in last meter of urban delivery to dominate parking problem where delivery areas are not sufficiently provided.

- Drone is a rather new technology to make possible aerial goods transportation in urban area.

Flows can be classified through this information in different manner, although it seems more efficient to make targeted classifications according to the intended application. Regarding our objective, pooling integration in city logistics, we intend to classify the flows in a way that enables us to analyse and evaluate scenarios defined by solutions combination as explained in the sections III. It is worth to mention that storage and means of transport alternatives are occasionally considered as city logistics solutions. The proposed ToF makes it possible to choose the most compatible solution of storage and/or means of transport for each type of flow, regarding features of flows such as: goods characteristics, demand and path. It is accepted that there is still a need to study, analyse and evaluate the different scenarios to choose the most profitable combination of solutions regarding the variety of urban flows. It is also expected that the variety of urban flows may require more than one means of transport or storage solution to guarantee an effective, environmentfriendly and sustainable delivery and distribution in urban area. This claim again the importance of goods flows identification to facilitate the decisions on solutions combination.

\section{CONCLUSION AND FUTURE RESEARCH}

The difficulty to implement successful city logistics initiatives and prosper them in long term horizon has become a debatable topic in recent years [13]. The complexity and dynamics of logistics systems especially in urban area motived us to focus on this field by the aim of system apprehension and elaboration. The first contribution of this study is the proposition of a general framework which describes how to integrate pooling into the city logistics system gradually and the second one is the proposition of a new concept: "Typology of Flow" which elaborates the city logistics system to identify its main elements. This tool is introduced to carry out the identification step of the first part of the proposed framework. These contributions help to study more profoundly the possibility of pooling according each type of flow and the suitable solutions of pooling (storage or means of transport). Quantifying urban flows, scenarios definition according to compatible solutions combination for the flows and their assessment are our future research directions.

\section{ACKNOWLEDGMENT}

The Support from Academic Research Communities (ARC8), Auvergne-Rhône-Alpes, France for funding this research is gratefully acknowledged.

\section{REFERENCES}

[1] Lee, H.L., 2014. Urbanisation proceeding on unprecedented scale. World Cities Summit, Marina Bay Sands, Singapore.

[2] Alho, A. R., \& e Silva, J. D. A. (2015). Utilizing urban form characteristics in urban logistics analysis: a case study in Lisbon, Portugal. Journal of Transport Geography, 42, 57-71.

[3] Thompson, R. G., \& Taniguchi, E. (2008). City logistics and freight transport. In Handbook of logistics and supply-chain management (pp. 393-405). Emerald Group Publishing Limited.

[4] Rao, C., Goh, M., Zhao, Y., \& Zheng, J. (2015). Location selection of city logistics centers under sustainability. Transportation Research Part D: Transport and Environment, 36, 29-44.

[5] Crainic, T. G., \& Laporte, G. (1997). Planning models for freight transportation. European journal of operational research, 97(3), 409-438.

[6] Dablanc, L (2009). Freight transport for development toolkit: Urban freight. The World Bank, Waszyngton.

[7] Dablanc, L., \& Rodrigue, J. P. (2017). The geography of urban freight. The Geography of Urban Transportation, 34.

[8] Rodrigue, J.P. (2013). Urban goods transport. In planning and design for sustainable urban mobility: Global Report on Human Settlements 2013 (United Nations Human Settlements Programme). London: Earthscan.

[9] Gonzalez-Feliu, J., \& Battaia, G. (2017). La mutualisation des livraisons urbaines: quels impacts sur les coûts et la congestion? Logistique \& Management, 25(2), 107-118.

[10] Morana, J., Gonzalez-Feliu, J., \& Semet, F. (2014). Urban consolidation and logistics pooling. In Sustainable urban logistics: Concepts, methods and information systems (pp. 187-210). Springer Berlin Heidelberg.

[11] Dolati Neghabadi, P., Evrard Samuel, K. and Espinouse, M.L. (2016). City Logistics: A Review and Research Framework, in RIRL 2016 EPFL.

[12] Gonzalez-Feliu, J., \& Morana, J. (2011). Collaborative transport sharing: From theory to practice via a case study from France. Technologies for supporting reasoning communities and collaborative decision making: Cooperative approaches. Hershey: IGI Global, 237251.

[13] Schmitt, A. J., Sun, S. A., Snyder, L. V., \& Shen, Z. J. M. (2015). Centralization versus decentralization: Risk pooling, risk diversification, and supply chain disruptions. Omega, 52, 201-212.

[14] Rouquet, A., \& Vauché, L. (2015, January). A Typology of Logistics Pooling in Supply Chains. In Supply Chain Forum: An International Journal (Vol. 16, No. 2, pp. 2-12). Taylor \& Francis.

[15] Ferreira, J. C., Martins, A. L., \& Pereira, R. (2017, June). GoodsPooling: An Intelligent Approach for Urban Logistics. In International Symposium on Ambient Intelligence (pp. 55-62). Springer, Cham. 
[16] Makaci, M., Reaidy, P., Evrard-Samuel, K., Botta-Genoulaz, V., \& Monteiro, T. (2017). Pooled warehouse management: An empirical study. Computers \& Industrial Engineering.

[17] Durand, B., Mahjoub, S., \& Senkel, M. P. (2014). La livraison des internautes urbains. 10èmes Rencontres Internationales de la Recherche en Logistique (RIRL).

[18] Durand, B. (2017). L'évaluation des centres de distribution urbaine: les limites de la modélisation. Logistique \& Management, 25(2), 131-146.

[19] Gonzalez-Feliu, J., \& Morana, J. (2014). Assessing urban logistics pooling sustainability via a hierarchic dashboard from a group decision perspective. In Sustainable Logistics (pp. 113-135). Emerald Group Publishing Limited.

[20] European Union (2014) Eurostat regional yearbook 2014. Luxembourg: Publications Office of the European Union. ISBN 978-92-79-38906-1 ISSN 2363-1716.

[21] [21] Gatta, V., Marcucci, E., \& Le Pira, M. (2017). Smart urban freight planning process: integrating desk, living lab and modelling approaches in decision-making. European Transport Research Review, 9(3), 32.9(3), 32 .

[22] Lindholm, M. (2010). A sustainable perspective on urban freight transport: Factors affecting local authorities in the planning procedures. Procedia-Social and Behavioral Sciences, 2(3), 6205-6216.

[23] Marcucci, E., Gatta, V., Marciani, M., \& Cossu, P. (2017). Measuring the effects of an urban freight policy package defined via a collaborative governance model. Research in Transportation Economics.

[24] Commission of the European Communities. Full evaluation report satellite based traffic management for smes.Technicalreport,www.civitas.eu/index.php?id=79\\&sel $\backslash$ menu=23 $\backslash$ \&measure $\backslash$ id $=250,2009$.

[25] Morana, J., \& Gonzalez-Feliu, J. (2014). A hierarchic sustainability dashboard to evaluate logistics pooling.

[26] Pan, S., Ballot, E., \& Fontane, F. (2013). The reduction of greenhouse gas emissions from freight transport by pooling supply chains. International Journal of Production Economics, 143(1), 86-94.
[27] Macário, R. (2013). Modeling for public policies inducement of urban freight business development. In Freight Transport Modelling (pp. 405432). Emerald Group Publishing Limited.

[28] Cattaruzza, D., Absi, N., Feillet, D., \& González-Feliu, J. (2017). Vehicle routing problems for city logistics. EURO Journal on Transportation and Logistics, 6(1), 51-79.

[29] Dablanc, L., Giuliano, G., Holliday, K., \& O'Brien, T. (2013). Best practices in urban freight management: Lessons from an international survey. Transportation Research Record: Journal of the Transportation Research Board, (2379), 29-38.

[30] Crainic, T. G., \& Sgalambro, A. (2014). Service network design models for two-tier city logistics. Optimization Letters, 8(4), 1375-1387.

[31] http://www.businessdictionary.com/

[32] Evrard Samuel, K., Cung, V.D. (2015). Towards evaluation tools for last mile delivery projects: insights from france, 6th METRANS International Urban Freight Conference, Long Beach CA, USA, October 21-23.

[33] Verlinde, S., Macharis, C., Milan, L., \& Kin, B. (2014). Does a mobile depot make urban deliveries faster, more sustainable and more economically viable: results of a pilot test in Brussels. Transportation Research Procedia, 4, 361-373.

[34] Hofmann, W., Assemen, T., Dolati Neghabadi, P., Cung, V-D., Tolujevs, J, (2017). Simulation tool to assess the ontegration of cargo bikes into an urban distribution system. 14th International Multidisciplinary Modelling \& Simulation. Barcelone, 2017.

[35] Dablanc, L. (2012). City logistics. The International Encyclopedia of Geography.

[36] Holguín-Veras, J., Amaya-Leal, J., Wojtowicz, J., Jaller, M., GonzálezCalderón, C., Sánchez-Díaz, I., \& Frazier, R. J. (2015). Improving freight system performance in metropolitan areas: a planning guide (No. Project
NCFRP-38). 


\section{Appendices}

Table 1. Fixed Features: Goods characteristics and Classification

\begin{tabular}{|c|c|c|}
\hline Goods Characteristics & Description & Classification \\
\hline Dimension & $\begin{array}{l}\text { It specifies goods physical dimension: Width, } \\
\text { Height, Depth. }\end{array}$ & Small/ Medium/Large \\
\hline Weight & It specifies goods weight. & Light/Average/ Heavy \\
\hline Transport unit & $\begin{array}{l}\text { Goods are transported in their own special } \\
\text { transport units. }\end{array}$ & $\begin{array}{c}\text { Parcel/ Pallet/ Cloths } \\
\text { rack/ Carcass/ Roll/ } \\
\text { Box/Crate/ }\end{array}$ \\
\hline Safety regulations & $\begin{array}{l}\text { Some goods require safety concerns as they } \\
\text { have a dangerous feature. }\end{array}$ & $\begin{array}{l}\text { Corrosive/Flammable/ } \\
\text { Explosive/ Toxic }\end{array}$ \\
\hline Safety requirements & $\begin{array}{l}\text { Several goods are precious so they need more } \\
\text { attention during their transportation. }\end{array}$ & Ordinary/ Precious \\
\hline Shipment Condition: & & \\
\hline $\begin{array}{l}\text { - Temperatures controlled } \\
\text { - Liquid/ Gas }\end{array}$ & $\begin{array}{l}\text { Several goods require special facilities in order } \\
\text { not to lose their quality. } \\
\text { Goods who are liquid or gas need technical } \\
\text { and sanitary cares. For instances, they may } \\
\text { need special cargos and safety control during } \\
\text { transportation. }\end{array}$ & $\begin{array}{l}\text { Frozen goods/ Fresh } \\
\text { goods (fruit, vegetable, } \\
\text { plant, flower and etc.)/ } \\
\text { Pharmaceutical products } \\
\text { Chemical goods/ } \\
\text { Petrochemical goods/ } \\
\text { Mining }\end{array}$ \\
\hline Handling concerns & $\begin{array}{l}\text { - In some cases, goods have some intrinsic } \\
\text { features that make them sensitive. So they } \\
\text { need to be handled carefully in order to keep } \\
\text { their quality and no to be destroyed. For } \\
\text { instance: if rice or flour bags is torn it would } \\
\text { become useless. } \\
\text { - In some other cases, handling concerns cope } \\
\text { with facilities requested for transportation } \\
\text { (loading/ unloading) as whether goods are too } \\
\text { large or heavy to be moved. }\end{array}$ & $\begin{array}{c}\text { Fragile/ Delicate/ } \\
\text { Sensitive to shock, } \\
\text { vibration, etc. / Bulky }\end{array}$ \\
\hline
\end{tabular}


Table 2. Variable Feature: Demand Characteristics and Classification

\begin{tabular}{|l|l|c|}
\hline \multicolumn{1}{|c|}{ Demand } & \multicolumn{1}{|c|}{ Description } & \multicolumn{1}{|c|}{ Classification } \\
\hline Orders quantity & $\begin{array}{l}\text { The quantity of demand is considered as } \\
\text { requested number of unit of transport of a good }\end{array}$ & Small/ Medium/Large \\
\hline Prediction of demand & $\begin{array}{l}\text { Whether it is possible to predict a demand or not } \\
\text { is predictability of demand. }\end{array}$ & $\begin{array}{c}\text { Regular/ Sporadic/ } \\
\text { Emergency }\end{array}$ \\
\hline Frequency of demand & $\begin{array}{l}\text { Interval in which a demand arrives is considered } \\
\text { as frequency of demand. }\end{array}$ & Daily/ Weekly/ Monthly/ \\
\hline Delivery lead time & $\begin{array}{l}\text { The desired time for a customer to receive his } \\
\text { command once he ordered it. }\end{array}$ & $\begin{array}{l}\text { One hours/One day/ One } \\
\text { week/... }\end{array}$ \\
\hline Seasonality & $\begin{array}{l}\text { This feature determines if the demand for the } \\
\text { good is seasonal or not. }\end{array}$ & Yes/ No \\
\hline Time window & $\begin{array}{l}\text { It means the desired delivery time for reception } \\
\text { point. It can be determined as a preference or } \\
\text { due to an obligation. For instance, the } \\
\text { newspaper has to be received in early morning. } \\
\text { Cloths could be received at any time, But a } \\
\text { receiver may prefer to be delivered in the } \\
\text { evening when his store is empty of client. }\end{array}$ & $\begin{array}{c}\text { Morning/ Afternoon/ } \\
\text { pvecise delivery time }\end{array}$ \\
\hline
\end{tabular}


Table 3. Variable Feature: Path Characteristics and Classification

\begin{tabular}{|c|c|c|}
\hline Path & Description & Classification \\
\hline Distance & Distance between origin and reception point. & Short/ Average/ Long \\
\hline \multicolumn{3}{|l|}{ District characteristics : } \\
\hline - Traffic state & $\begin{array}{l}\text { Traffic state depends on the schedule, it will be } \\
\text { used in the further steps when a tour is planned. }\end{array}$ & Crowded/Spacious \\
\hline - Access condition & $\begin{array}{l}\text { The condition to enter to a district is considered } \\
\text { as access condition. May a district be forbidden } \\
\text { for some type of means of transport due to } \\
\text { regulations or its own structural or } \\
\text { infrastructural features? }\end{array}$ & $\begin{array}{l}\text { Access restricted area/ } \\
\text { Narrow street/ Access } \\
\text { only permitted for } \\
\text { specified mean of } \\
\text { transport }\end{array}$ \\
\hline - Geographical condition & $\begin{array}{l}\text { Where a district is situated is important to } \\
\text { identify requirements to serve it. }\end{array}$ & $\begin{array}{l}\text { On a hill/ On a flat/ On } \\
\text { an island }\end{array}$ \\
\hline - Risk assessment & $\begin{array}{l}\text { It specifies the condition of being protected } \\
\text { from theft or injury in a district. }\end{array}$ & Priority security zones \\
\hline Reception point & $\begin{array}{l}\text { It shows whether the reception point is a } \\
\text { retailer (B2B) or a home delivery (B2C). }\end{array}$ & $\begin{array}{l}\text { Retailer delivery/ Home } \\
\text { delivery }\end{array}$ \\
\hline $\begin{array}{l}\text { Reception point } \\
\text { accessibility }\end{array}$ & $\begin{array}{l}\text { The location of a reception point is important to } \\
\text { perform last meter delivery. The condition to } \\
\text { reach a reception point specifies this } \\
\text { classification. }\end{array}$ & $\begin{array}{l}\text { Easy to access/ Access } \\
\text { only by walk (pedestrian } \\
\text { area)/Impossible to } \\
\text { access directly }\end{array}$ \\
\hline Delivery area & $\begin{array}{l}\text { If there is an available delivery area in the } \\
\text { proximity of the reception point. }\end{array}$ & $\begin{array}{l}\text { Does not exist/ } \\
\text { Available with } \\
\text { reservation/ Available } \\
\text { but it is far/ Available } \\
\text { anytime }\end{array}$ \\
\hline
\end{tabular}

